\title{
Liver resections for metastasis: surgical outcomes of a single center academic institution
}

Phillipe Abreu ${ }^{1,2,3^{*}+}$ (1), Raphaella Ferreira ${ }^{1,2+}$, Danilo Saavedra Bussyguin ${ }^{1}$, Eduardo DaCás ${ }^{1}$, Vighnesh Vetrivel Venkatasamy ${ }^{3}$, Flávio Daniel Saavedra Tomasich ${ }^{4 \dagger}$ and Luiz Arnaldo Szutan ${ }^{2 \dagger}$

\begin{abstract}
Background: Hepatic metastasis are frequent and liver resection may be an option for some cases, despite the high complexity of the procedure and the possibility of postoperative complications.

Methods: This retrospective comparative descriptive study aims to evaluate a series of 86 consecutive liver resections (LRs) performed for the treatment of metastatic liver tumors, comparing the results between patients undergoing major and minor LR. All patients submitted to LR from October 2010 to July 2015 at the Erasto Gaertner Hospital in Curitiba-PR were included. Quantitative numerical variables were analyzed with the Student t-test. The nonparametric Mann-Whitney U test was used for numerical variables of non-normal distribution. Categorical variables were analyzed with the Chi-square test with Fisher's correction. The data were analyzed with the SPSS 23.0 and STATA 15 programs, being $\mathrm{p}<0.05$ considered statistically significant.
\end{abstract}

Results: Eighty-six LR were performed, 56 cases by colorectal metastasis. The major LR corresponded to 68 cases, with $13.2 \%$ of Clavien-Dindo III-V complications and $2.9 \%$ of reoperation rate. Eighteen minor LR were performed and one patient had a postoperative complication requiring reoperation.

Conclusion: Preoperative elevation of transaminases and jaundice negatively influence surgical outcomes in patients undergoing LR. Tumors greater than $3 \mathrm{~cm}$ presented worse postoperative survival. Major LR did not significantly increase the surgical morbidity rate.

Institutional Review Board registration: 1.122.319/2015

Keywords: Liver resection, Hepatectomy, Liver tumors, Liver metastases, Postoperative complications

\section{Background}

Secondary hepatic tumors are frequent because the liver is the main solid organ affected by hematogenic metastases [1]. The main origins of these metastases are cancers

\footnotetext{
*Correspondence: Dr.PhillipeAbreu@gmail.com

${ }^{\dagger}$ Phillipe Abreu and Raphaella Ferreira have contributed equally as first authors.

†Flávio Daniel Saavedra Tomasich and Luiz Arnaldo Szutan have contributed equally as senior authors.

1 Erasto Gaertner Hospital, Centro de Projetos de Estudo E Pesquisa (CEPEP), Curitiba, PR, Brazil

Full list of author information is available at the end of the article
}

of the colon, pancreas, ovary, rectum, stomach, lungs and kidneys [1]. Liver resection (LR) is an option to treat colorectal metastases with a 5-years overall survival of approximately $70 \%$ [2]. Neuroendocrine tumors liver metastases can also be treated with LR, with a 5-year survival of 60 to $80 \%$ [3].

There is a progressive trend in the indication of surgical approaches in hepatic metastases, due to the advance in tumor response to chemotherapy treatment, allowing the resection of tumors that initially exceeded the limits of resectability [4]. 
Liver surgery for the treatment of colorectal metastasis should aim at R0 resection, saving two segments adjacent to the resected segment and allowing the inflow and outflow of independent blood and bile drainage [5]. The future liver remnant should have no less than 25 and $30 \%$ of the total liver volume in cirrhotic and noncirrhotic patients, respectively [6].

Currently, there is a tendency to perform parenchymalspearing LRs, obtaining oncologic resection with minimal margins, decreasing the risk of postoperative liver failure and allowing future LRs when necessary [7].

The extent of LR is based on the preoperative evaluation of the patient. Residual parenchyma, presence of portal hypertension and hypoalbuminemia should be evaluated [8]. Patients with non-cirrhotic livers can tolerate a resection of up to $75 \%$ of its volume or up to 6 segments, but patients with Child-Pugh B or C livers have high rates of complications even when undergoing minor LRs [9]. Therefore, the preoperative evaluation should be individualized according to the particularities of each case [8].

The surgical morbidity of LRs varies in different studies due to differences in the categorization of complications, being estimated between 4.1 to $47.7 \%$ [10]. Clavien-Dindo's classification was described in 2004 with the aim of standardizing the evaluation of postoperative complications in an objective and reproducible manner [11]. It consists of five degrees: I-any deviation from normality postoperatively, without the need for surgical, endoscopic, radiological or pharmacological interventions (except anti-emetic, antipyretic, analgesic, diuretic and electrolyte drugs); II-need for pharmacological treatment (beyond that allowed in degree I); III-need for surgical, endoscopic or radiological intervention; IV-life-threatening complications; V-death [11].

The most dramatic of the complications described is the postoperative acute liver failure, related to the amount of liver tissue removed and previous liver function [12]. Biliary fistula has a prevalence of 4 to $17 \%$. Post-operative bleeding may be present in up to $8 \%$ of hepatectomies [5]. Several thromboembolic phenomena are cited, such as venous thrombosis and pulmonary thromboembolism, as well as thrombosis of hepatic vein and portal vein [13]. Other complications can include acute renal failure, ascites, wound infection, intrahepatic abscesses and pneumonia [14]. LR has high technical complexity and should be performed in specialized and reference centers [12].

\section{Methods}

This retrospective comparative descriptive study aims to evaluate the surgical outcomes of hepatectomies performed in an oncologic teaching hospital affiliated to the
Brazilian Unified Health System. All patients submitted to LR from October 2010 to July 2015 at the Erasto Gaertner Hospital in Curitiba-PR, Brazil were included. Written informed consent form was obtained from all subjects. The project was approved by the institutional review board under the number 1.122.319/2015. All methods were carried out in accordance with relevant guidelines and regulations.

\section{Surgical indications}

Resection in metastatic disease of tumors of several primary etiologies, which met criteria of anatomic resectability, after good response to systemic treatment, was indicated. Liver metastasis diagnosed at the same time or up to 6 months after the diagnose of the primary tumor were considered as synchronic metastases. Liver metastasis diagnosed after 6 months of primary diagnosis were considered as metacronic metastases. As a routine, we do not perform liver resections in the same surgical procedure as the primary tumor resection, due to increased morbidity and mortality when compared to staged resections $[15,16]$, although safely performed in selected centers [17-19]. The order of resection to be performed is determined by the patient's symptoms, treating first the most symptomatic tumor.

\section{Diagnostic and preoperative workup}

The preoperative evaluation of the cardiovascular, pulmonary, renal, hepatic, nutritional and anesthetic systems was performed in all patients undergoing LR, and may have some variation depending on the underlying disease. Recent imaging (less than 45 days) is mandatory to perform the procedure.

\section{Study variables}

The clinical characteristics of the patients and the underlying disease, Performance-Status (PS), laboratory tests of liver function, type of liver resection, associated surgical procedures, need for transfusion, length of stay, mortality and postoperative complications following the ClavienDindo classification were collected and analyzed.

\section{Characteristics of the surgical procedure}

Vast majority of the cases were open Liver resections, only 4 cases performed by minimally invasive technique. All open resections were performed with intra-operative sonographic analysis of the lesions and careful delimitation or their limits with ultrasound assessment. In all cases hilar vascular control was performed by intermittent Pringle Maneuver (15-20 min clamped dissection, followed by $15-20 \mathrm{~min}$ of unclamped dissection). Patients were transferred to Intensive Care Unit (ICU) of the hospital for postoperative care. 


\section{Study groups}

The patients were divided into groups according to the surgery performed. Group I= major LR (resection of at least 3 liver segments or resection involving the segment IV) and Group II = minor LR. Minor resections included anatomic resections and wedge resections. Major resections included central, right and left resections, depending on the tumor locations. Due to the nature of intra-hepatic metastatic spread, there was a high heterogeneity of the procedure performed, thus the option of recording the data according to the number of segments resected reflected as the best option to standardize groups for analysis in relation to the hepatic volume.

\section{Statistical analysis}

The data were expressed as mean and standard deviation or as median and interquartile range for non-normal distribution. Quantitative numerical variables were analyzed with the Student t-test. The nonparametric Mann-Whitney $U$ test was used for numerical variables of non-normal distribution. Categorical variables were analyzed with the Chi-square test with Fisher's correction. The data were analyzed with the SPSS 23.0 and STATA 15 programs, being $\mathrm{p}<0.05$ considered statistically significant.

Survival analysis A survival sub-analysis was performed with a univariable comparison. The factors that were taken into consideration in this analysis are: the presence of preoperative jaundice, the presence of high values of transaminases (AST and ALT) in the preoperative period, the type of resection performed (greater or lesser) and the size of the injury (greater or lesser than $3.0 \mathrm{~cm})$.

\section{Results}

In the period analysed, 86 LRs were performed. The median age of the patients was 56.1 years (IQR 45.965.8). Thirty-eight (44.2\%) patients were male. Other epidemiological data are presented in Table 1.

Sixty-eight (79.1\%) major hepatectomies (group I) and 18 (20.9\%) minor hepatectomies (group II) were performed. Group I presented 48 patients (72.7\%) with ASA 2 , while group II presented $13(76.5 \%)(p=0.93)$. The mean time of surgery was $205 \mathrm{~min}$ (IQR 122.5-300.0) in group I and $180 \mathrm{~min}$ (IQR 120.0-300.0) in group II $(\mathrm{p}=0.49)$.

The overall rate of postoperative complications Clavien-Dindo III or higher was $11.6 \%$ with 9 patients (13.2\%) in Group I and 1 patient (5.6\%) in Group II $(\mathrm{p}$-value $=0.36)$. The global rate of reoperation was $3.5 \%$, 2 patients $(2.9 \%)$ of group I and 1 patient (5.6\%) of group II $(\mathrm{p}=0.59)$.

Group I presented 56 surgeries $(82.4 \%)$ with anatomical resection, while Group II presented 5 (27.8\%), with

Table 1 Demographic characteristics and epidemiological profile of the sample

\begin{tabular}{|c|c|c|c|c|}
\hline Variable & $\begin{array}{l}\text { Total } \\
(n=86)\end{array}$ & $\begin{array}{l}\text { Colorectal } \\
(n=56)\end{array}$ & $\begin{array}{l}\text { Non-colorectal/non- } \\
\text { neuroendocrine }(n=30)\end{array}$ & p \\
\hline Death rate, number (\%) & $42(48.8)$ & $29(51.8)$ & $13(43.3)$ & 0.45 \\
\hline Recurrence rate, number (\%) & $48(55.8)$ & $34(60.7)$ & $14(46.7)$ & 0.21 \\
\hline Median follow-up, years (IQR) & $2.4(0.9-5.1)$ & $2.6(1.0-5.0)$ & $2.0(0.2-6.7)$ & 0.71 \\
\hline Sex, male (\%) & $38(44.2)$ & $24(42.9)$ & $14(46.7)$ & 0.73 \\
\hline Age, median years (IQR) & $56.1(45.9-65.8)$ & $58.4(46.6-65.8)$ & $52.0(43.2-63.1)$ & 0.24 \\
\hline ECOG-PS, number (\%) & & & & 0.002 \\
\hline 0 & $17(19.8)$ & $11(19.6)$ & $6(20.0)$ & \\
\hline 1 & $58(67.4)$ & $43(76.8)$ & $15(50.0)$ & \\
\hline 2 & $11(12.8)$ & $2(3.6)$ & $9(30.0)$ & \\
\hline $\mathrm{BMI}\left(\mathrm{kg} / \mathrm{m}^{2}\right),(\mathrm{QQR})$ & $25.0(23.5-27.6)$ & $25.2(23.5-27.7)$ & $25.0(23.0-26.7)$ & 0.84 \\
\hline History of smoking, number (\%) & $33(41.8)$ & $21(42.9)$ & $12(40.0)$ & 0.80 \\
\hline Smoking, packs-year (IQR) & $24.0(13.7-38.5)$ & $20.0(7.0-39.5)$ & $30.0(21.5-36.5)$ & 0.27 \\
\hline Hypertension and/or heart disease, number (\%) & $32(37.2)$ & $23(41.1)$ & $9(30.0)$ & 0.31 \\
\hline Family history of cancer, number (\%) & $13(20.3)$ & $9(21.4)$ & $4(18.2)$ & 0.75 \\
\hline Differentiation grade, number (\%) & & & & 0.02 \\
\hline Well differentiated & $25(29.1)$ & $11(19.6)$ & $14(46.7)$ & \\
\hline Moderately different & $48(55.8)$ & $36(64.3)$ & $12(40.0)$ & \\
\hline Poorly differentiated & $13(15.1)$ & $9(16.1)$ & $4(13.3)$ & \\
\hline Free margins, number (\%) & $77(89.5)$ & $47(83.9)$ & $30(100.0)$ & 0.02 \\
\hline
\end{tabular}

IQR interquartile range, ECOG-PS Eastern Cooperative Oncology Group - Performance Status, BMI Body Mass Index 
significant statistical difference $(\mathrm{p}<0.001)$. The median admission in group I was 5 days (IQR 3.0-7.0) while in group II was 3 days (IQR 3.0-6.0) $(\mathrm{p}=0.15)$. The mean time of ICU was 2 days (IQR 1.0-3.0) in group I and 2 days (IQR $0-2.2)$ in group II $(\mathrm{p}=0.12)$. There was no difference in the use of hemoderivatives between the groups, being 3 units of RBC concentrate in group I (IQR 2.0-4.0) and 3.5 in group II (IQR 2.0-6.0) $(\mathrm{p}=0.56)$.

Among the 86 LRs performed, 56 (65.1\%) were indicated by metastases of colorectal tumor, and 47 (69.1\%) were treated with major hepatectomy. Surgical outcomes are presented in Table 2 .

The mean actuarial global survival rate over 1,3 and 5 years was $69.7 \%, 40.6 \%$ and $27.9 \%$, respectively (Fig. 1a). Group I presented a mean survival rate of 9.3 years (IQR 6.6-12.0) and Group II 8.6 years (IQR 4.1-13.0) without significant difference $(\mathrm{p}=0.73)$ (Fig. 1b).

The preoperative elevation of transaminases (AST and ALT) showed significant influence on the mean survival of the sample. Patients with high preoperative AST had a mean survival of 6.1 years (IQR 2.2-10.0), while those with normal AST values achieved a mean survival of 9.5 years (IQR 7.0-12.1), $(\mathrm{p}=0.01)$ (Fig. 2a). In respect to the ALT values, the group with preoperative elevation achieved a mean survival of 2.9 years (IQR $0.1-5.7$ ) compared to 10.1 years (IQR 7.5-12.8) in the group with preoperative ALT normal values, $(\mathrm{p}=0.002)($ Fig. $2 \mathrm{~b})$.
When survival is compared between the groups with and without preoperative jaundice a significant difference is obtained ( $\mathrm{p}=0.02)$, with the non-jaundice group having a mean survival of 10.4 years (IQR 6.4-14.4) and the group with preoperative jaundice 4.8 years (IQR 0.0 10.2) (Fig. 3a).

The size of the lesion showed significant influence on survival $(p=0.03)$. Patients with tumors of up to $3.0 \mathrm{~cm}$ had a mean survival of 9.3 years (IQR 5.9-12.6), while those with tumors greater than $3.0 \mathrm{~cm}$ had a mean survival of 8.9 years (IQR 6.0-11.8) (Fig. 3b).

\section{Discussion}

Improved surgical technique and better knowledge of the physiological anatomy of the liver, combined with better diagnostic conditions, allowed LR to be performed more often in oncologic patients [20].

The largest indication for surgery in our sample was liver metastasis of colorectal cancer (65.1\% of cases). This number is in line with the current progressive trend to operate patients with colorectal metastasis due to the advance in chemotherapy treatment, which can provide a $50 \%$ survival over 5 years $[2,4]$. Major LR was the surgical approach used in these patients to perform a R0 resection.

The surgical outcomes of LRs are also described in other studies, such as Resende et al. which showed a rate of postoperative complications of $11.4 \%$, including

Table 2 Surgical data-major LR versus minor LR

\begin{tabular}{|c|c|c|c|c|}
\hline Variable & $\begin{array}{l}\text { Total } \\
(n=86)\end{array}$ & $\begin{array}{l}\text { Major LR } \\
(n=68)\end{array}$ & $\begin{array}{l}\text { Minor LR } \\
(n=18)\end{array}$ & $\mathbf{p}$ \\
\hline ASA, number (\%) & & & & 0.93 \\
\hline 1 & $10(12.0)$ & $8(12.1)$ & $2(11.8)$ & \\
\hline 2 & $61(73.5)$ & $48(72.7)$ & $13(76.5)$ & \\
\hline 3 & $12(14.5)$ & $10(15.2)$ & $2(11.8)$ & \\
\hline Hemotransfusion, number (\%) & $30(34.9)$ & $24(35.3)$ & $6(33.3)$ & 0.87 \\
\hline PRBC, units (IQR) & $3.0(2.0-4.0)$ & $3.0(2.0-4.0)$ & $3.5(2.0-6.0)$ & 0.56 \\
\hline Surgical time, minutes, median (IQR) & $200.0(120.0-300.0)$ & $205.0(122.5-300.0)$ & $180.0(120.0-300.0)$ & 0.49 \\
\hline Pos-operative complications Clavien III-V, number (\%) & $10(11.6)$ & $9(13.2)$ & $1(5.6)$ & 0.36 \\
\hline Reoperation, number (\%) & $3(3.5)$ & $2(2.9)$ & $1(5.6)$ & 0.59 \\
\hline Lenght of stay, days, median (IQR) & $4.0(3.0-6.2)$ & $5.0(3.0-7.0)$ & $3.0(3.0-6.0)$ & 0.15 \\
\hline ICU time, days, median (IQR) & $2.0(1.0-3.0)$ & $2.0(1.0-3.0)$ & $2.0(0.0-2.2)$ & 0.12 \\
\hline Lesion size, cm (IIQ) & $3.5(2.7-5.0)$ & $3.5(2.7-5.0)$ & $4.0(3.0-5.0)$ & 0.54 \\
\hline Number of lesions (IQR) & $1.0(1.0-3.0)$ & $1.0(1.0-2.0)$ & $1.0(1.0-1.2)$ & 0.57 \\
\hline Vascular involvement, number (\%) & $23(26.7)$ & $18(26.5)$ & $5(27.8)$ & 0.91 \\
\hline Colorectal tumor, number (\%) & $56(65.1)$ & $47(69.1)$ & $9(50.0)$ & 0.13 \\
\hline First LR, number (\%) & $77(89.5)$ & $61(89.7)$ & $16(88.9)$ & 0.92 \\
\hline Anatomical ressection, number (\%) & $61(70.9)$ & $56(82.4)$ & $5(27.8)$ & $<0.001$ \\
\hline Synchronic tumor, number of patients (\%) & $18(32.1)$ & $16(23.5)$ & $2(11.1)$ & 0.48 \\
\hline
\end{tabular}

$I Q R$ interquartile range, $A S A$ American Society of Anesthesiologists, ICU Intensive Care Unit, $L R$ liver resection, $P R B C$ packed red blood cell 
a

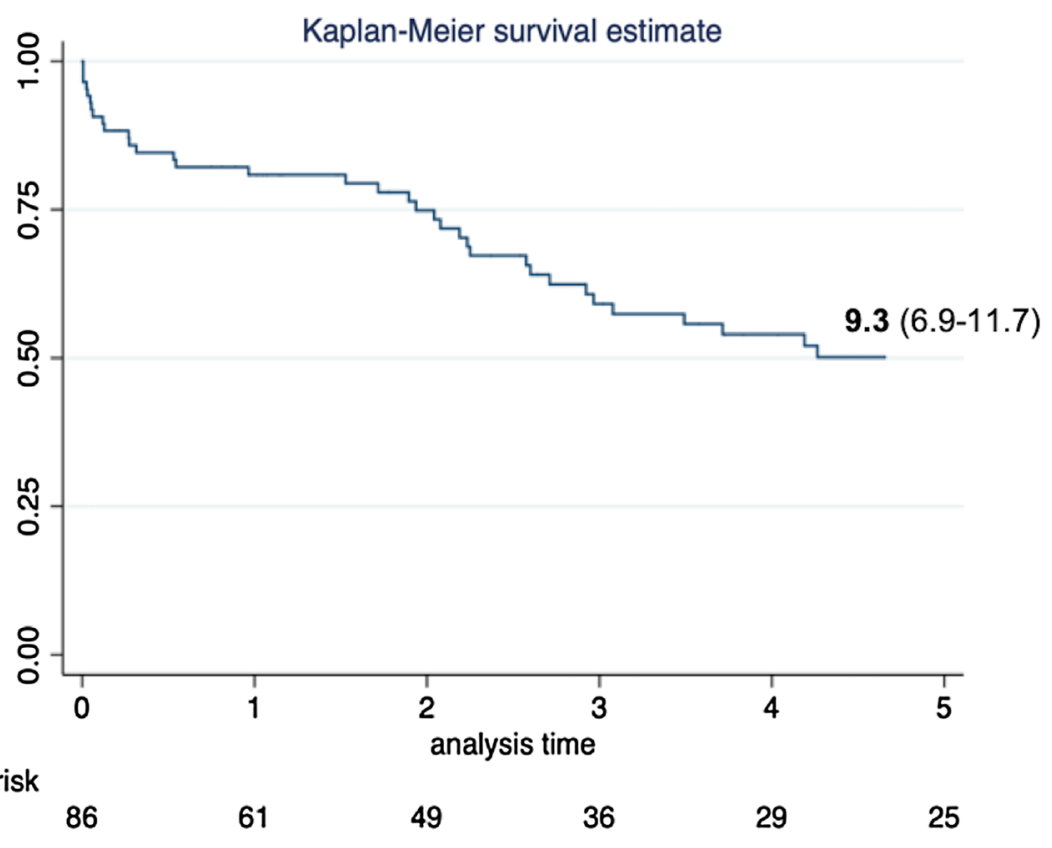

b

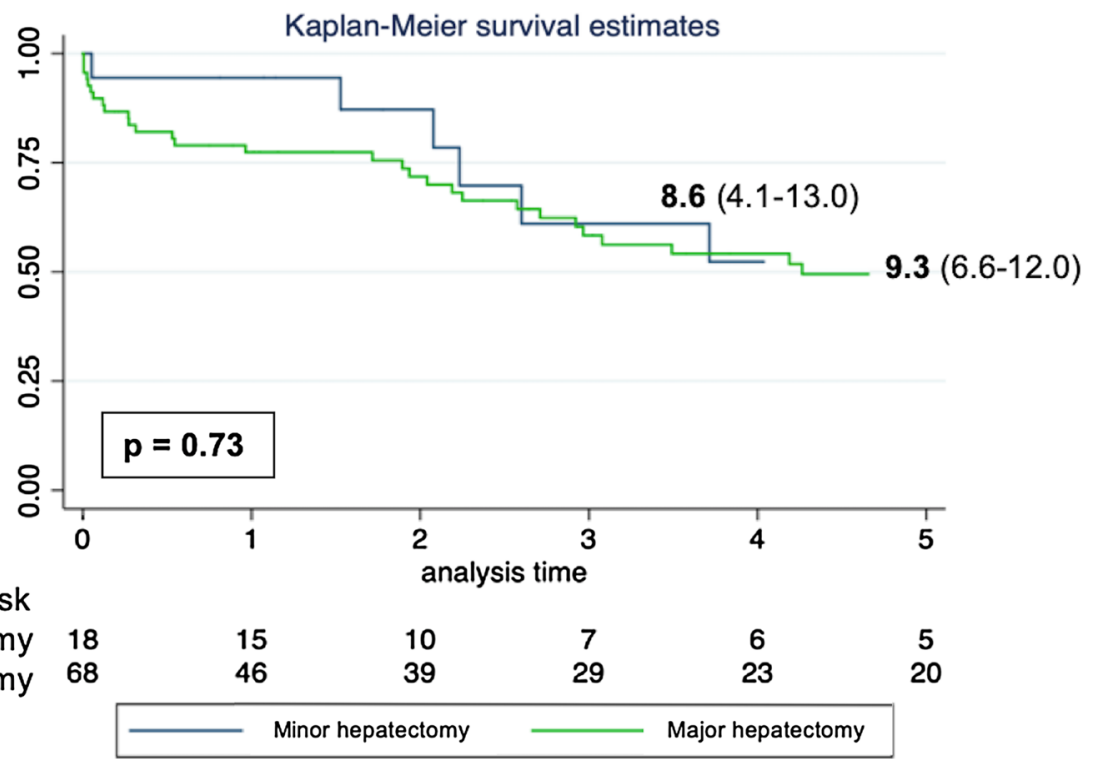

Fig. 1 Overall Survival in years. a Complete cohort. b Stratified by the type of LR performed

non-oncologic cases [21]. Other authors such as Amico et al. show complication rates of $14.7 \%$, highlighting intraperitoneal collection, pleural effusion and hemorrhage [20]. In both national studies there was a higher rate of postoperative complications in patients undergoing major LRs.

Our study presented an overall rate of postoperative complications of $11.6 \%$, even including a large percentage of major LRs (79.6\%) - higher than the percentages found in other Brazilian series, with $31.4 \%$ and $43.2 \%$ [20, 21].
Considering that the complication rates have progressive increase according to the extent of LR, these values are in line with those found in literature [8].

Complication rates are also related to functional disability of the liver, and patients with Child-Pugh B or C scores have high incidence of postoperative complications, limiting in some cases the performance of major LRs [9]. Since our sample included, in its majority, patients operated for colorectal metastasis and not for hepatocellular carcinoma (a condition that predisposes 
a
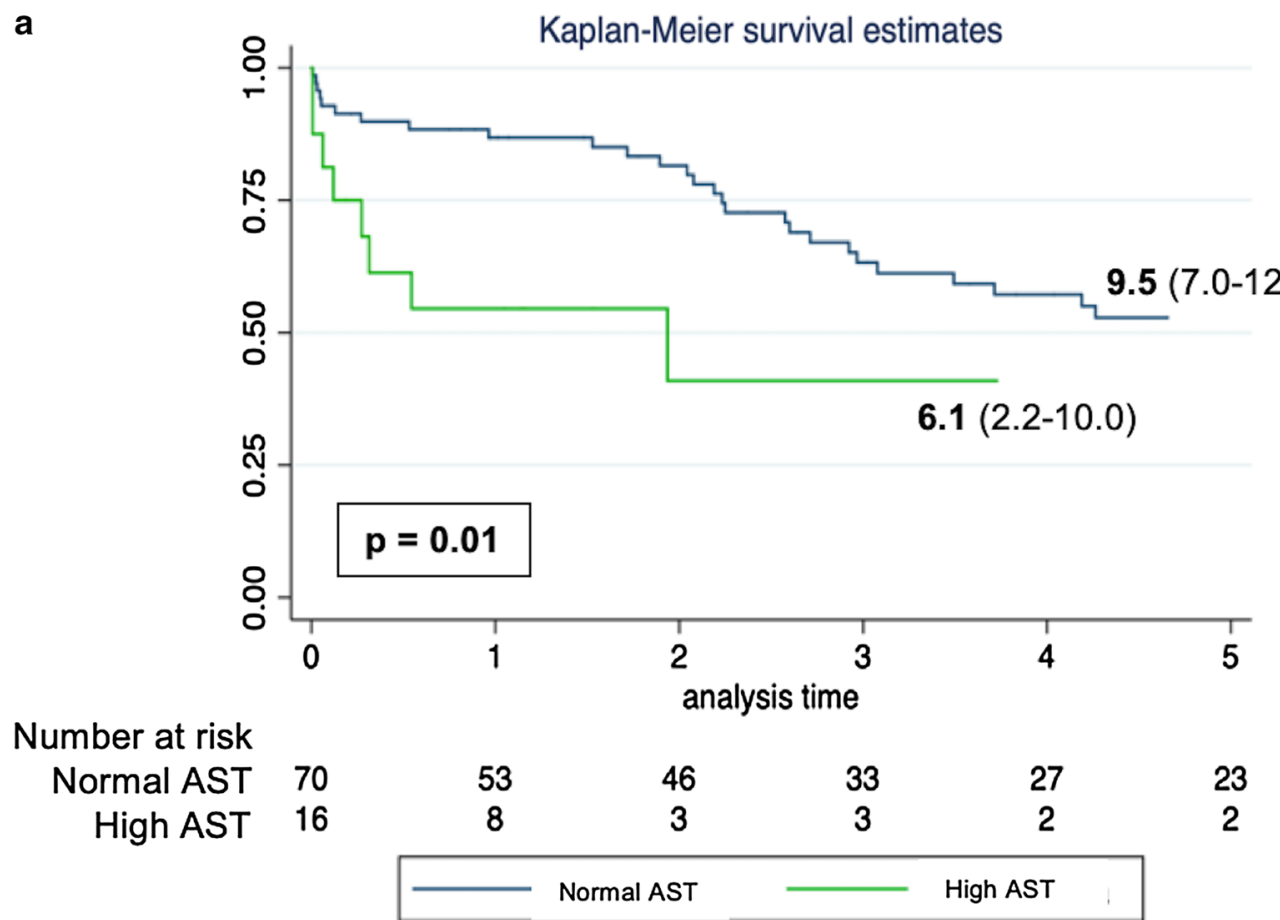

b

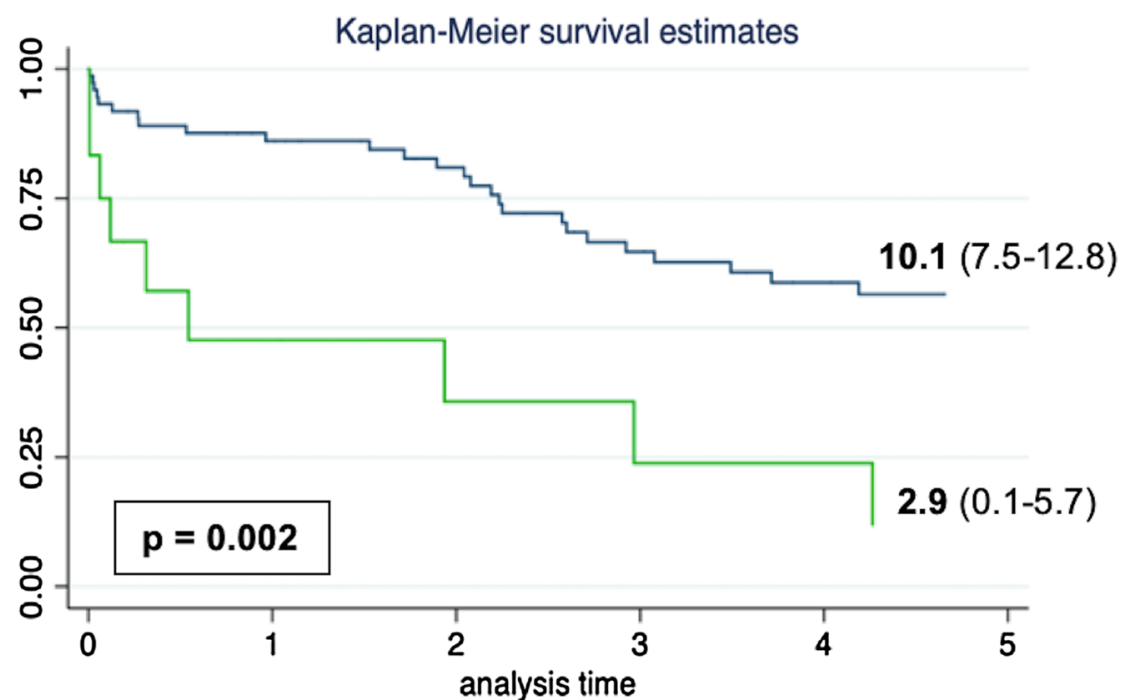
Number at risk
Normal ALT 74
High ALT 12

56
5

$\begin{array}{cc}46 & 34 \\ 3 & 2\end{array}$

27

24

Normal ALT

High ALT

Fig. 2 Overall Survival in years by groups. a Stratified by preoperative values of AST. b Stratified by preoperative values of ALT

to liver cirrhosis and functional limitation of the liver), it is justified to perform major LRs in $69.1 \%$ of these cases.

However, patients with hepatic functional changes (preoperative elevation of AST, ALT and bilirubin) presented significantly more postoperative complications in our sample, which reinforces the need for careful prior evaluation of future liver remnant [22]. Tian et al. analyzed 74 patients undergoing LR for hepatocellular carcinoma and concluded that the presence of preoperative jaundice is directly related to the patient's prognosis [23]. 
a

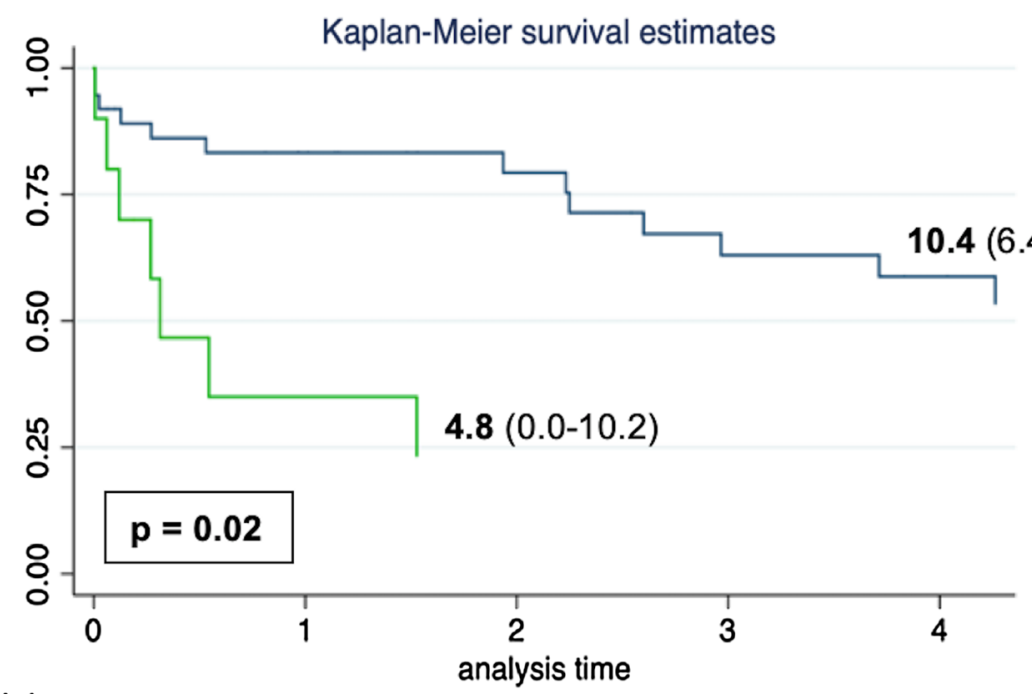

\section{Number at risk \\ No jaundice Jaundice}

37
10

\begin{tabular}{|c|ccc|}
\hline 26 & 20 & 15 & 12 \\
3 & 2 & 2 & 2 \\
\hline & No jaundice & & \\
\hline
\end{tabular}

b

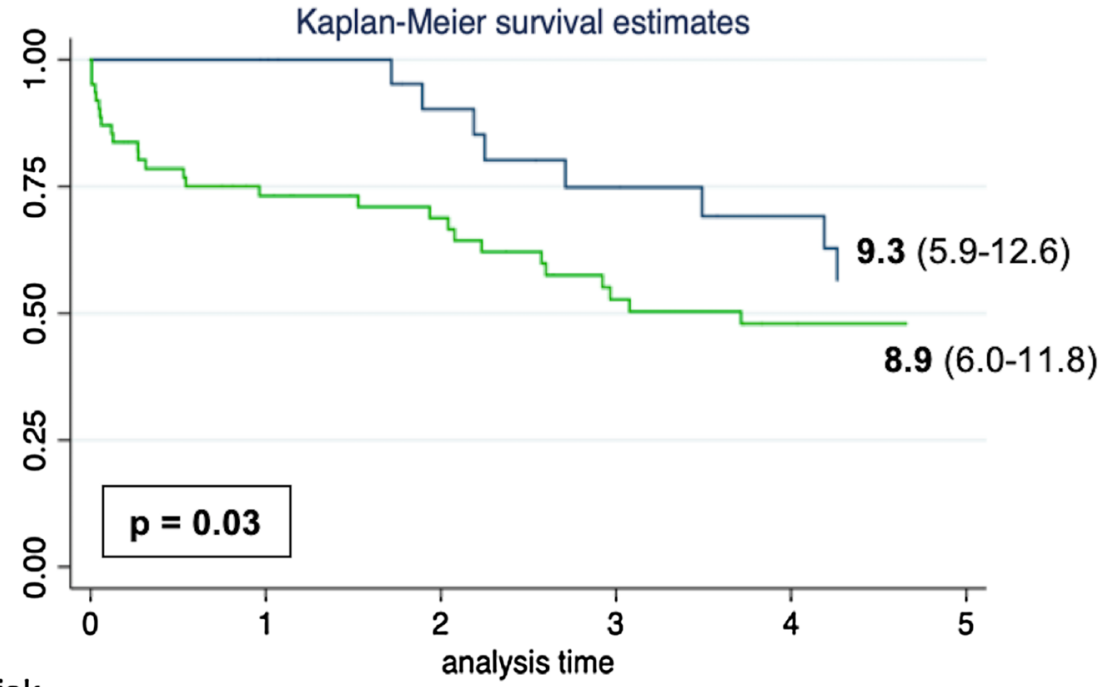
Number at risk $\leq 3 \mathrm{~cm}$ lesion $>3 \mathrm{~cm}$ lesion

\begin{abstract}
18
\end{abstract}
31

\section{4}

22

$\begin{array}{cc}11 & 9 \\ 18 & 16\end{array}$

$\leq 3 \mathrm{~cm}$ lesion

$>3 \mathrm{~cm}$ lesion

Fig. 3 Overall Survival in years by groups of interest. a Stratified by the presence of preoperative jaundice. $\mathbf{b}$ Stratified by tumor size in centimeters

Lesions of larger diameters in general require more extensive resections, which can lead to further postoperative complications. The difference in the number of complications between major and minor LRs is described by Virani et al., but in our analysis there was no significant difference between the two groups $(p=0.36)$ [24]. It is worth noting that only one patient undergoing minor LR presented postoperative complications with the need for surgical reopening. The sample size did not allow a statistically significant difference in the rate of complications between major and minor LR, but with the expansion of the study it is likely that this difference is 
confirmed, following the pattern in the literature [24]. However, we found a significant difference in survival of patients with tumors larger than $3 \mathrm{~cm}$, which showed no direct correlation with the type of resection performed.

While the overall rate of reoperation described in the literature is $5.2 \%$ [24], our sample presented an overall rate of only $3.5 \%$, demonstrating technical suitability of the service.

We understand as limitations of our study as uncontrolled retrospective characteristic. There are also limitations of technological resources due to the work being performed in a public Unified Health System teaching hospital where there are budgetary restrictions.

\section{Conclusion}

We can conclude that preoperative elevation of transaminases and jaundice negatively influence surgical outcomes in patients undergoing LRs. Tumors greater than $3 \mathrm{~cm}$ presented worse postoperative survival. Major LR did not significantly increase the surgical morbidity rate.

\begin{abstract}
Abbreviations
ALT: Alanine aminotransferase; ASA: American Society of Anesthesiologists; AST: Aspartate aminotransferase; BMI: Body Mass Index; ECOG-PS: Eastern Cooperative Oncology Group - Performance Status; ICU: Intensive Care Unit; IQR: Interquartile range; LR: Liver resection; PRBC: Packed red blood cell.
\end{abstract}

\section{Acknowledgements}

Not applicable.

\section{Authors' contributions}

DSB and EC collected patient data. RF and PA analyzed and interpreted patient data, contributed to the writing of the manuscript. WV contributed to the writing of the manuscript. FDST and LAS contributed to study conception, and writing of the manuscript. All authors read and approved the final manuscript.

\section{Funding}

Not applicable.

\section{Availability of data and materials}

The datasets used and analysed during the current study are available from the corresponding author on reasonable request.

\section{Ethics approval and consent to participate}

The project was approved by the institutional review board of the Erasto Gaertner Hospital - Brazil under number 1.122.319/2015. Written informed consent form was obtained from all subjects.

\section{Consent for publication}

Not applicable.

\section{Competing interests}

The authors declare that they have no competing interests.

\section{Author details}

${ }^{1}$ Erasto Gaertner Hospital, Centro de Projetos de Estudo E Pesquisa (CEPEP), Curitiba, PR, Brazil. ${ }^{2}$ Faculdade de Ciências Médicas da Santa Casa de São Paulo, Departamento de Cirurgia, Área de Fígado e Hipertensão Portal, São Paulo, SP, Brazil. ${ }^{3}$ Department of Surgery, University of Miami, Miami Transplant Institute, Jackson Memorial Hospital, Miami, FL, USA. ${ }^{4}$ Hospital Erasto Gaertner, Curitiba, PR, Brazil.
Received: 16 July 2020 Accepted: 21 October 2020

Published online: 27 October 2020

\section{References}

1. Kooby DA, Stockman J, Ben-Porat L, Gonen M, Jarnagin WR, Dematteo RP, et al. Influence of transfusions on perioperative and long-term outcome in patients following hepatic resection for colorectal metastases. Ann Surg. 2003;237(6):860-70.

2. House MG, Ito H, Gönen M, Fong Y, Allen PJ, DeMatteo RP, et al. Survival after hepatic resection for metastatic colorectal cancer: trends in outcomes for 1,600 patients during two decades at a single institution. J Am Coll Surg. 2010;210(5):744-52.

3. Mayo SC, De Jong MC, Pulitano C, Clary BM, Reddy SK, Gamblin TC, et al. Surgical management of hepatic neuroendocrine tumor metastasis: results from an international multi-institutional analysis. Ann Surg Oncol. 2010;17(12):3129-36.

4. Brouquet A, Abdalla EK, Kopetz S, Garrett CR, Overman MJ, Eng C, et al. High survival rate after two-stage resection of advanced colorectal liver metastases: response-based selection and complete resection define outcome. J Clin Oncol. 2011;29(8):1083-90.

5. Ann M, Cabús S, Inostroza M, Chahdi M, Paul D, David R, et al. Defining benchmarks for major liver surgery defining benchmarks for major liver surgery a multicenter analysis of 5202 living liver donors. Ann Surg. 2016;264:492-500.

6. Sharma S, Camci C, Jabbour N. Management of hepatic metastasis from colorectal cancers: an update. J Hepatobiliary Pancreat Surg. 2008:15(6):570-80.

7. Araujo RLC, Cesconetto D, Jeismann VB, Fonseca GM, Coelho FF, Kruger JAP, et al. Central hepatectomy for biliary cystadenoma: parenchymasparing approach for benign lesions. Arq Bras Cir Dig. 2016;29(4):295-6.

8. Paes-Barbosa FC, Ferreira FG, Szutan LA. Planejamento pré-operatório em hepatectomias. Rev Col Bras Cir. 2010;37(5):370-5.

9. Mullin EJ, Metcalfe MS, Maddern GJ. How much liver resection is too much? Am J Surg. 2005;190(1):87-97.

10. Spolverato G, Ejaz A, Hyder O, Kim Y, Pawlik TM. Failure to rescue as a source of variation in hospital mortality after hepatic surgery. Br I Surg. 2014;101(7):836-46.

11. Dindo D, Demartines N, Clavien P. Classification of surgical complications. Ann Surg. 2004;240(2):205-13.

12. Rössler F, Sapisochin G, Song G, Lin Y-H, Simpson MA, Hasegawa K, et al. Defining benchmarks for major liver surgery: a multicenter analysis of 5202 living liver donors. Ann Surg. 2016;264(3):492-500.

13. Majella MB, Majella MB, Muller X, Marcon ÃF, Sapisochin G, Marquez M, et al. Defining benchmarks in liver transplantation : a multicenter outcome analysis determining best achievable results defining benchmarks in liver transplantation. Ann Surg. 2018;267:419-25.

14. Ishii M, Mizuguchi T, Harada K, Ota S, Meguro M, Ueki T, et al. Comprehensive review of post-liver resection surgical complications and a new universal classification and grading system. World J Hepatol. 2014;6:745-51.

15. Hajibandeh S, Hajibandeh S, Sultana A, Ferris G, Mwendwa J, Mohamedahmed AYY, et al. Simultaneous versus staged colorectal and hepatic resections for colorectal cancer with synchronous hepatic metastases: a meta-analysis of outcomes and clinical characteristics. Int J Colorect Dis. 2020;35:1629-50

16. Nitsche U, Weber C, Kaufmann B, von Figura G, Assfalg V, Miller G, et al. Simultaneous versus staged resection of colorectal cancer liver metastasis: a retrospective single-center study. J Surg Res. 2020;255:346-54.

17. Capussotti L, Ferrero A, Viganò L, Ribero D, Tesoriere R, Polastri R. Major liver resections synchronous with colorectal surgery. Ann Surg Oncol. 2007;14(1):195-201.

18. De Raffele E, Mirarchi M, Vaccari S, Cuicchi D, Lecce F, Dalla Via B, et al. Intermittent clamping of the hepatic pedicle in simultaneous ultrasonography-guided liver resection and colorectal resection with intestinal anastomosis: is it safe? Int J Colorectal Dis. 2014;29(12):1517-25.

19. Martin RCG, Augenstein V, Reuter NP, Scoggins CR, McMasters KM. Simultaneous versus staged resection for synchronous colorectal cancer liver metastases. J Am Coll Surg. 2009;208(5):842-50. 
20. Amico EC, Alves JR, João SA, Guimarães PLFC, de Medeiros JAC, Barreto ÉJSS. Immediate complications after 88 hepatectomies - Brazilian consecutive series. Arq Bras Cir Dig. 2016;29(3):180-4.

21. Resende V, Rezende-Neto JB, Fernandes JS, Cunha-Melo JR. Assessment of morbidity and mortality after hepatic resections. Rev Col Bras Circ. 2011;38(5):323-6.

22. Hasselgren $K$, Sandström P, Björnsson B. Role of associating liver partition and portal vein ligation for staged hepatectomy in colorectal liver metastases: a review. World J Gastroenterol. 2015:21(15):4491-8.

23. Tian YL, Ji JJ, Chen LN, Cui XL, Li BB, Liu ST, et al. Risk factors for long-term prognosis of hepatocellular carcinoma patients after anatomic hepatectomy. World J Clin Cases. 2020;8(4):713-22.
24. Virani S, Michaelson JS, Hutter MM, Lancaster RT, Warshaw AL, Henderson WG, et al. Morbidity and mortality after liver resection: results of the patient safety in surgery study. J Am Coll Surg. 2007;204(6):1284-92.

\section{Publisher's Note}

Springer Nature remains neutral with regard to jurisdictional claims in published maps and institutional affiliations.
Ready to submit your research? Choose BMC and benefit from:

- fast, convenient online submission

- thorough peer review by experienced researchers in your field

- rapid publication on acceptance

- support for research data, including large and complex data types

- gold Open Access which fosters wider collaboration and increased citations

- maximum visibility for your research: over 100M website views per year

At BMC, research is always in progress.

Learn more biomedcentral.com/submissions 